\title{
Oxazolidine Derivatives as Corrosion Inhibitors for API X60 Steel in 1 M HCl Solution: Experimental and Theoretical Studies
}

\author{
Nuha Wazzan ${ }^{1, *}$, I. B. Obot ${ }^{2}$,Hassan Faidallah ${ }^{1}$ \\ ${ }^{1}$ King Abdulaziz University, College of Science, Chemistry Department, Jeddah, Saudi Arabia \\ ${ }^{2}$ Centre of Research Excellence in Corrosion, Research Institute, King Fahd University of Petroleum \\ and Minerals, Dhahran 31261, Saudi Arabia \\ *E-Mail: nwazzan@kau.edu.sa
}

doi: $10.0964 / 2019.08 .02$

Received: 13 January 2019 / Accepted: 3 April 2019 / Published: 30 June 2019

Some synthesized oxazolidine derivatives (1-oxa-4-azaspiro [4,4]nonane, 1-oxa-4-azaspiro [4,5]decane, 6-methyl-1-oxa-4-azaspiro [4,5]decane and 1-oxa-4-azaspiro [4,7]dodecane) have been tested as promising inhibitors for API 5L X60 steel corrosion in a $1 \mathrm{M} \mathrm{HCl}$ solution using weight loss and electrochemical techniques complemented with computational studies. Characterization of the synthesized compounds was achieved using ${ }^{1} \mathrm{H}$ and ${ }^{13} \mathrm{C}$ NMR spectroscopic analysis. The oxazolidine derivatives could efficiently lower the corrosion rate of the steel sample during $24 \mathrm{~h}$ of immersion in an acidic medium. The oxazolidine derivatives have minimal effect on the corrosion potential of steel in the acid solution. Their adsorption onto the steel surface effectively improved the charge transfer resistance, and the oxazolidine compounds acted as mixed-type inhibitors. A cyclooctyl substitution at the $\mathrm{C}-11$ position produced the highest inhibitor efficiency, and attachment of a methyl group could enhance the inhibition efficiency of the cyclohexyl substituent at the $\mathrm{C}-11$ position. Density functional theory calculations were conducted to gain insight into the structural and electronic properties of the four corrosion inhibitors and their inhibitory effects.

Keywords: Oxazolidine Derivatives; Electrochemistry; Corrosion inhibitors; DFT; Steel; Acid corrosion.

\section{FULL TEXT}

(C) 2019 The Authors. Published by ESG (www.electrochemsci.org). This article is an open access article distributed under the terms and conditions of the Creative Commons Attribution license (http://creativecommons.org/licenses/by/4.0/). 